\title{
Mitochondrial control of platelet apoptosis: effect of cyclosporin A, an inhibitor of the mitochondrial permeability transition pore
}

\author{
Valery Leytin ${ }^{1,2,3,4}$, David J Allen ${ }^{1}$, Asuman Mutlu ${ }^{1}$, Armen V Gyulkhandanyan ${ }^{1}$, Sergiy Mykhaylov ${ }^{1}$ and \\ John Freedman 1,2,3,4
}

The role of the mitochondrial permeability transition pore (MPTP) in apoptosis of nucleated cells is well documented. In contrast, the role of MPTP in apoptosis of anucleated platelets is largely unknown. The aim of this study was to elucidate the contribution of MPTP in the control of different manifestations of platelet apoptosis by analyzing the effect of cyclosporin A (CsA), a potent inhibitor of MPTP formation. Using flow cytometry, we studied the effect of pretreatment of platelets with CSA on apoptotic responses in human platelets stimulated with calcium ionophore A23187. We found that CsA inhibited A23187-stimulated platelet apoptosis, completely preventing (i) depolarization of mitochondrial inner membrane potential $(\Delta \Psi \mathrm{m})$, (ii) activation of cytosolic apoptosis executioner caspase-3, (iii) platelet shrinkage, and (iv) fragmentation of platelets to microparticles, but $(v)$ only partially $(\approx 25 \%)$, inhibiting phosphatidylserine (PS) exposure on the platelet surface. This study shows that MPTP formation is upstream of $\Delta \Psi \mathrm{m}$ depolarization, caspase-3 activation, platelet shrinkage and microparticle formation, and stringently controls these apoptotic events in A23187-stimulated platelets but is less involved in PS externalization. These data also indicate that CsA may rescue platelets from apoptosis, preventing caspase- 3 activation and inhibiting the terminal cellular manifestations of platelet apoptosis, such as platelet shrinkage and degradation to microparticles. Furthermore, the results suggest a novel potentially useful application of CsA as an inhibitor of platelet demise through apoptosis in thrombocytopenias associated with enhanced platelet apoptosis.

Laboratory Investigation (2009) 89, 374-384; doi:10.1038/labinvest.2009.13; published online 23 February 2009

KEYWORDS: calpain inhibitor calpeptin; caspase-3 activation; cyclosporin A; mitochondrial inner membrane depolarization; mitochondrial permeability transition pore; phosphatidylserine exposure, platelet shrinkage and microparticle formation

Mitochondria are known as the 'power factories' of the cell, which supply energy required for cell life. However, another, quite unexpected, function of mitochondria has been documented providing strong evidence that they also play a key role in the control of cell apoptosis. ${ }^{1-5}$ Apoptosis, or programmed cell death, is the physiological mechanism that serves for controlled deletion of unwanted cells. ${ }^{3,6}$ Since its discovery, ${ }^{7}$ apoptosis was long attributed exclusively to nucleated cells, in which it was shown that the formation of mitochondrial permeability transition pore (MPTP) is a critical event in mitochondrial control of apoptosis, responsible for depolarization of mitochondrial inner trans- membrane potential $(\Delta \Psi \mathrm{m})$, permeabilization of inner and outer mitochondrial membrane, and subsequent release of proapoptotic proteins (such as cytochrome $c$ and apoptosisinducing factor) from mitochondria to cytosol. ${ }^{1-5,8}$ MPTP is a channel which spans the inner and outer mitochondrial membranes and consists of multiple proteins, including the protein from the inner mitochondrial membrane (adenine nucleotide translocator, ANT), and the ANT-interacting mitochondrial matrix protein cyclophilin $\mathrm{D}(\mathrm{CypD})$, an essential regulator of MPTP formation. ${ }^{2,9,10}$ Although the role of ANT is debated, ${ }^{11-13}$ the role of CypD in the MPTP opening beyond doubt. ${ }^{2,9,10,12,13}$ Cyclosporin A (CsA), that

\footnotetext{
'Division of Transfusion Medicine, Department of Laboratory Medicine, The Keenan Research Centre in the Li Ka Shing Knowledge Institute of St. Michael's Hospital, Toronto, ON, Canada; ${ }^{2}$ Toronto Platelet Immunobiology Group, Toronto, ON, Canada; ${ }^{3}$ Department of Laboratory Medicine and Pathobiology, University of Toronto, Toronto, ON, Canada and ${ }^{4}$ Department of Medicine, University of Toronto, Toronto, ON, Canada

Correspondence: Dr V Leytin, PhD, Division of Transfusion Medicine, St. Michael's Hospital, 30 Bond St, Toronto, ON, Canada M5B 1W8.

E-mail: leytinv@smh.toronto.on.ca

Received 19 September 2008; revised 3 December 2008; accepted 19 December 2008
} 
interacts with CypD, is a well-known potent inhibitor of MPTP formation in isolated mitochondria and intact nucleated cells. ${ }^{2,5,8,13}$

Over the past decade it has been recognized that apoptosis also occurs in anucleated cytoplasts ${ }^{14-16}$ and platelets. ${ }^{17-31}$ In contrast to nucleated cells, where the pivotal role of the mitochondrion in the control of apoptosis is well documented, the role of mitochondrial control of apoptosis in platelets is largely unknown. Although platelets lack a nucleus and nuclear DNA, they do contain mitochondria and mitochondrial DNA ${ }^{32-34}$ and metabolically stable mRNA and are capable of protein synthesis. ${ }^{35-37}$ Mitochondria contribute significantly to the energy metabolism of platelets. ${ }^{32}$

We have shown that diverse stimuli induce $\Delta \Psi \mathrm{m}$ depolarization in platelets, including the soluble platelet agonists thrombin $^{26,28}$ and calcium ionophore A23187,, ${ }^{24,26}$ antiglycoprotein (GP) IIb antibody, ${ }^{27}$ pathologically high shear stresses $^{24}$ and long-term incubation of platelets under blood banking conditions. ${ }^{26,31}$ Others, using rabbit and dog models, have shown the decrease of $\Delta \Psi \mathrm{m}$ in circulating platelets during aging of platelets in vivo. ${ }^{25,38}$ Mitochondria-associated apoptotic markers, caspase- 9 and proapoptotic members of Bcl-2 family, as well as activation of executioner caspase-3 have also been shown to be induced in human and mouse platelets both in vitro and in vivo under an appropriate stimulation. ${ }^{17-22,24,26-31}$

Recently, the role of MPTP in the formation of a human platelet sub-population corresponding to 'coatedplatelets' (platelets costimulated with collagen mimetic and GPVI agonist convulxin + thrombin) has been shown, as measured by the effect of CsA on coated-platelet markersfibrinogen retention, calcein release and phosphatidylserine (PS) exposure. ${ }^{39}$ A key role for CypD was also shown in murine-coated platelets, using CypD-deficient $\left(\mathrm{CypD}^{-1-}\right)$ and CypD-positive $\left(\mathrm{CypD}^{+1+}\right)$ control mice: $\mathrm{CypD}^{-1-}$ platelets exhibited reduced $\Delta \Psi \mathrm{m}$ depolarization and PS exposure, and decreased surface retention of high-level fibrinogen. ${ }^{40}$

Although MPTP formation and $\Delta \Psi \mathrm{m}$ depolarization were defined as early manifestations of apoptosis in nucleated cells, ${ }^{1,2,4,8}$ the terminal 'degradation phase' of apoptosis is characterized by PS externalization on the plasma membrane surface and morphological alterations at the whole-cell level, such as cell shrinkage and shedding of membrane-enclosed vesicles, apoptotic bodies. ${ }^{5}$ These terminal manifestations of apoptosis were also shown in platelets after exposure to very high pathological shear stresses. ${ }^{24}$

The aim of this study was to elucidate the role of MPTP in the terminal manifestations of platelet apoptosis by analyzing the effect of CsA on PS exposure, platelet shrinkage and shedding of platelet microparticles in platelets stimulated with A23187, which is a known strong inducer of these platelet responses. ${ }^{23,26,41}$ Quantitative comparison of the CsA effect on mitochondrial ( $\Delta \Psi \mathrm{m}$ depolarization), cytoplasmic (caspase-3 activation), plasma membrane (PS exposure) and cellular (platelet shrinkage and microparticle formation) apoptotic events was also performed to evaluate, using 'CsAdependency test,' the relative contribution of MPTP in the control of mitochondrial, executioner and terminal phases of platelet apoptosis.

\section{MATERIALS AND METHODS Reagents and Solutions}

Bovine serum albumin (BSA), dimethylsulfoxide (DMSO) and 4-(2-hydroxyethyl)-1-piperazineethanesulfonic acid (HEPES) and CsA were purchased from Sigma (St Louis, MO, USA), paraformaldehyde was purchased from Polysciences (Warrington, PA, USA), A23187 was purchased from Calbiochem (San Diego, CA, USA) and calpeptin ( $N$-benzyloxycarbonyl-L-leucylnorleucinal) was purchased from Tocris Bioscience (Ellisville, MO, USA). Fluorescein isothiocyanate (FITC)-conjugated anti-GPIIbIIIa antibody (anti-CD41-FITC, clone P2) was purchased from BeckmanCoulter (Westbrook, ME, USA) and phycoerythrin (PE)conjugated annexin $\mathrm{V}$ was purchased from BD Biosciences (San Jose, CA, USA). JC-1 (5,5',6,6'-tetrachloro- $1,1^{\prime}, 3$, $3^{\prime}$-tetraethylbenzimidazolyl-carbocyanine iodide) was purchased from Invitrogen (Carlsbad, CA, USA) and FAMDEVD-FMK (carboxyfluorescein-carbonyl-aspartyl-glutamylvalyl-aspartic acid fluoromethyl ketone) was purchased from Chemicon International (Temecula, CA, USA). Buffer A was composed of phosphate-buffered saline (Invitrogen) supplemented with $1 \mathrm{mM} \mathrm{MgCl} 2,5.6 \mathrm{mM}$ glucose, $0.1 \%$ BSA and $10 \mathrm{mM}$ HEPES, pH 7.4. Buffer B was composed of buffer A containing $0.5 \%$ DMSO. Stock solutions of CsA $(10 \mathrm{mM})$ and A23187 (12 mM) were dissolved in DMSO, aliquots were stored at $-80^{\circ} \mathrm{C}$ and after thawing just before use, working solutions were prepared by 1:200 dilution of stock solutions with buffer $\mathrm{A}$ to obtain required concentrations of CsA $(50 \mu \mathrm{M})$ and A23187 $(60 \mu \mathrm{M})$ in buffer A containing $0.5 \%$ DMSO.

\section{Preparation and Treatment of Platelets with CsA and A23187}

Venous blood from healthy volunteers was anticoagulated with $0.32 \%$ sodium citrate. Platelet-rich plasma (PRP) was obtained by centrifugation at $180 \mathrm{~g}$ for $15 \mathrm{~min}$ at room temperature (RT), and platelet count was determined by a Coulter LH750 Analyzer (Beckman-Coulter, Miami, FL, USA).

Platelet-rich plasma was diluted 1:10 with buffer A (for $\Delta \Psi \mathrm{m}$, caspase-3, platelet shrinkage and microparticle assays) and 1:60 with buffer A (for PS assay), and apoptotic events were determined in four groups of platelet samples: (i) buffer B-treated platelets, (ii) CsA- plus buffer B-treated platelets, (iii) A23187-treated platelets and (iv) CsA- plus A23187treated platelets. All platelet treatment procedures were performed in a total volume of $30 \mu \mathrm{l}$. For buffer B-treated platelets (used as the DMSO-diluent control for CsA and A23187 treatments), $20 \mu \mathrm{l}$ of diluted PRP aliquots were 
incubated with $10 \mu \mathrm{l}$ buffer B for $45 \mathrm{~min}$ at RT. For CsA- plus buffer B-treated platelets, $20 \mu$ l of diluted PRP aliquots were preincubated for $30 \mathrm{~min}$ at RT with $5 \mu \mathrm{l}$ buffer A containing $50 \mu \mathrm{M}$ CsA and $0.5 \%$ DMSO, followed by incubation for 15 min at RT with $5 \mu \mathrm{l}$ buffer B. For A23187-treated platelets, $20 \mu$ l of diluted PRP aliquots were preincubated for $30 \mathrm{~min}$ at RT with $5 \mu \mathrm{l}$ buffer B, followed by incubation for $15 \mathrm{~min}$ at RT with $5 \mu \mathrm{l}$ buffer A containing $60 \mu \mathrm{M} \mathrm{A} 23187$ and $0.5 \%$ DMSO. For CsA- plus A23187-treated platelets, $20 \mu \mathrm{l}$ of diluted PRP aliquots were preincubated for $30 \mathrm{~min}$ at RT with $5 \mu \mathrm{l}$ buffer A containing $50 \mu \mathrm{M}$ CsA and $0.5 \%$ DMSO, followed by incubation for $15 \mathrm{~min}$ at RT with $5 \mu$ l buffer A containing $60 \mu \mathrm{M} \mathrm{A} 23187$ and $0.5 \%$ DMSO.

In some experiments, platelets were titrated with CsA concentrations $(0,1,10$ and $100 \mu \mathrm{M})$ or the effect of the duration of CsA (15, 30 and $60 \mathrm{~min})$ and $\mathrm{A} 23187$ (15, 30 and $60 \mathrm{~min})$ treatment was studied.

\section{Treatment of Platelets with Calpeptin and A23187}

Platelet-rich plasma was diluted 1:7.5 with buffer A (for $\Delta \Psi \mathrm{m}$ and caspase-3 assays) and 1:45 with buffer A (for PS assay), and apoptotic events were determined in three groups of platelet samples: (i) buffer B-treated platelets, (ii) A23187treated platelets and (iii) calpeptin- plus A23187-treated platelets. All platelet treatments were performed in a total volume of $30 \mu \mathrm{l}$. For buffer B-treated platelets (used as the DMSO-diluent control for calpeptin and A23187 treatments), $15 \mu \mathrm{l}$ of diluted PRP aliquots were incubated with $15 \mu \mathrm{l}$ buffer B for $45 \mathrm{~min}$ at RT. For A23187-treated platelets, $15 \mu$ l of diluted PRP aliquots were preincubated for $30 \mathrm{~min}$ at RT with $10 \mu \mathrm{l}$ buffer B, followed by incubation for $15 \mathrm{~min}$ at RT with $5 \mu \mathrm{l}$ buffer A containing $60 \mu \mathrm{M} \mathrm{A} 23187$ and $0.5 \%$ DMSO. For calpeptin- plus A23187-treated platelets, $15 \mu \mathrm{l}$ of diluted PRP aliquots were preincubated for $30 \mathrm{~min}$ at RT with $10 \mu \mathrm{l}$ buffer A containing $500 \mu \mathrm{M}$ calpeptin and $0.5 \%$ DMSO, followed by incubation for $15 \mathrm{~min}$ at RT with $5 \mu$ l buffer A containing $60 \mu \mathrm{M} \mathrm{A} 23187$ and $0.5 \%$ DMSO. As was shown earlier in titration experiments, ${ }^{42}$ this concentration of calpeptin $(200 \mu \mathrm{M}$ final $)$ strongly inhibited the shedding of microparticles from agonist-treated platelets.

\section{Determination of Platelet Apoptotic Responses}

Platelet apoptosis was analyzed in four groups of appropriately treated platelet samples (see above) by flow cytometry (FACSCalibur, BD Biosciences). Depolarization of $\Delta \Psi \mathrm{m}$, caspase-3 activation, PS exposure, and platelet shrinkage and fragmentation to microparticles were used for characterizing mitochondrial, cytoplasmic, plasma membrane and cellular manifestations of platelet apoptosis, respectively.

Depolarization of $\Delta \Psi \mathrm{m}$ was measured by the cell-penetrating lipophilic cationic fluorochrome JC-1, which accumulates in mitochondrial matrix, driven by $\Delta \Psi \mathrm{m} .^{2,24,27}$ The JC-1 stock solution $(2 \mathrm{mg} / \mathrm{ml}$ in DMSO) was diluted with buffer A to a final concentration of $1-2 \mu \mathrm{g} / \mathrm{ml}$, mixed by vortex, incubated in the dark for $15 \mathrm{~min}$ at RT and centrifuged for $15 \mathrm{~min}$ at $16000 \mathrm{~g}$ in $1.5 \mathrm{ml}$ Eppendorf tubes in an Eppendorf 5415C microfuge (Eppendorf, Westbury, NY, USA). The supernatants were harvested, combined and used immediately as the JC-1 working solution in the $\Delta \Psi \mathrm{m}$ depolarization assay. Aliquots $(30 \mu \mathrm{l})$ of treated platelets were incubated in the dark for $30 \mathrm{~min}$ at $37^{\circ} \mathrm{C}$ with $470 \mu$ l of JC- 1 working solution, and samples were acquired for flow cytometry. Platelets were gated by characteristic light forward scatter (FSC) - side scatter (SSC) dot plots and plateletbound JC-1 monomers (fluorescence 1, FL1) and JC-1 aggregates (fluorescence 2, FL2) were analyzed as FL1-FL2 dot plots. Depolarization of $\Delta \Psi \mathrm{m}$ was quantified as an increase of the percentage depolarized cells, which reflects the decrease in content of JC-1 aggregates when the inner mitochondrial membrane becomes depolarized.

Caspase-3 activation was determined using the cell-penetrating fluorescein-labeled peptide inhibitor of caspase-3, FAM-DEVD-FMK, which covalently binds to active caspase- $3 .{ }^{22,24,26}$ Aliquots $(3.3 \mu \mathrm{l})$ of $10 \times$ working FAM-DEVDFMK solution, prepared according to the manufacturer's recommendations, were added to $30 \mu \mathrm{l}$ of treated platelet samples and incubated for $45 \mathrm{~min}$ at $37^{\circ} \mathrm{C}$ in the dark. Following dilution to $500 \mu \mathrm{l}$ with buffer A, samples were acquired within $30-60 \mathrm{~min}$ at low acquisition rate. Fluorescent (FL1) histograms were analyzed and caspase-3 activation was quantified as the mean channel fluorescence of platelet-bound FAM-DEVD-FMK.

Phosphatidylserine exposure in treated platelet samples was quantified by dual-color staining with annexin V-PE and anti-GPIIbIIIa-FITC antibody for $15 \mathrm{~min}$ at RT as described earlier ${ }^{27}$ and expressed as the percentage annexin V-positive cells.

Platelet shrinkage and microparticle formation were detected using platelet- and microparticle-specific anti-GPIIbIIIa antibody. Aliquots $(5 \mu \mathrm{l})$ of anti-GPIIbIIIa-FITC antibody were added to $30 \mu \mathrm{l}$ of treated platelets and incubated for $15 \mathrm{~min}$ at RT in the dark. Samples were fixed with $100 \mu \mathrm{l}$ of $1 \%$ paraformaldehyde in buffer A for $30 \mathrm{~min}$ at RT and diluted to $500 \mu \mathrm{l}$ with buffer A. After acquisition, the FSC-FL1 dot plots were analyzed and platelets and microparticles were identified in platelet- and microparticlespecific gates, respectively. ${ }^{24}$ Platelet shrinkage was determined by analyzing FSC histograms as the decrease of FSC characteristics of GPIIbIIIa-positive events in platelet gate and expressed as the mean FSC. Fragmentation of platelets to microparticles was quantified by counting GPIIbIIIa-positive events in microparticle gate; 20000 GPIIbIIIa-positive events were acquired totally in both platelet plus microparticle gates.

\section{Calculation of Inhibitory Effect of CsA on Apoptotic Responses}

To quantify the relative impact of CsA on different manifestations of platelet apoptosis, the inhibitory effect of CsA 
on A23187-induced apoptotic events was calculated for each apoptotic parameter. For A23187-upregulated apoptotic parameters $(\Delta \Psi \mathrm{m}$ depolarization, caspase-3 activation, PS exposure and microparticle formation), the percentage of inhibition $(I, \%)$ of apoptotic parameters by CsA was calculated by the formula:

$$
I(\%)=(\mathrm{A}-\mathrm{C}) \times 100 \% /(\mathrm{A}-\mathrm{B}),
$$

where $\mathrm{A}, \mathrm{B}$ and $\mathrm{C}$ are the values of apoptotic parameters after the treatment of platelets with A23187 (A), control diluent buffer (B) or CsA + A23187 (C).

For A23187-downregulated apoptotic parameter (platelet shrinkage), the percentage of inhibition was calculated by the formula:

$$
I(\%)=(\mathrm{C}-\mathrm{A}) \times 100 \% /(\mathrm{B}-\mathrm{A}) .
$$

\section{Statistical Analysis}

Data are presented as means \pm s.e.m. The statistical significance of the differences between different platelet groups was determined by paired Student's $t$-test and one-way ANOVA as appropriate. Differences were considered significant when $P<0.05$.

\section{RESULTS}

\section{Calcium lonophore A23187 Induces Apoptotic Events in} Human Platelets

Table 1 shows that calcium ionophore A23187 $(10 \mu \mathrm{M})$ triggers a number of apoptotic alterations in human platelets. As the result of A23187 treatment, an average of approximately $40 \%$ of platelets had depolarized $\Delta \Psi \mathrm{m}$, as measured by JC-1 staining, and $99 \%$ of the cells had exposed PS on their surface, as detected by annexin V binding (Table 1). Caspase- 3 activation was also observed, as measured by a 2.3-fold increase in the mean fluorescence of A23187-treated platelets stained with FAM-DEVD-FMK probe, which irreversibly binds to active caspase-3 (Table 1). Breakdown of platelets to microparticles was revealed as GPIIbIIIa-positive events in the microparticle gate: a 7.6-fold increase in the number of microparticles was observed following A23187 treatment (Table 1). Finally, platelet shrinkage was detected as a 1.5-fold decrease of the mean FSC of GPIIbIIIa-positive events in the platelet gate (Table 1). Assuming that FSC is directly proportional to the platelet size, this result indicates that A23187 causes a decrease in mean platelet size of 33\%.

\section{CsA Significantly Inhibits Apoptosis in A23187- stimulated Platelets}

To examine how inhibition of MPTP formation affects platelet apoptosis, A23187-stimulated platelets were preincubated with CsA and different apoptotic responses were analyzed in comparison with responses observed in platelets incubated with A23187 only. Pretreatment of platelets with $10 \mu \mathrm{M}$ CsA significantly inhibited all manifestations of platelet apoptosis induced by calcium ionophore, including $\Delta \Psi \mathrm{m}$ depolarization (Figure 1, $P=0.01$ ), caspase-3 activation (Figure 2, $P=0.02$ ), PS externalization (Figure 3, $P=0.04$ ), shedding of microparticles (Figure $4, P=0.002$ ) and platelet shrinkage (Figure 5, $P=0.002$ ).

\section{Quantification of Inhibitory Effect of CsA on Different Apoptotic Events in A23187-stimulated Platelets}

Figure 6 shows further quantitative analysis of the CsA inhibitory effect on different apoptotic parameters in A23187-induced platelets. This showed that CsA strongly inhibited $\Delta \Psi \mathrm{m}$ dissipation $(106.3 \pm 1.2 \%)$, platelet shrinkage $(118.3 \pm 13.4 \%)$, fragmentation of platelets to microparticles $(101.5 \pm 2.3 \%)$ and caspase- 3 activation $(85.9 \pm 8.3 \%)$, but only moderately $(23.9 \pm 7.9 \%)$ inhibited PS exposure (Figure 6). The mean inhibitory effect of CsA on $\Delta \Psi \mathrm{m}$ depolarization, platelet shrinkage and microparticle formation, calculated as described above (Materials and Methods), exceeded $100 \%$, reflecting the fact that CsA extremely efficiently inhibits these apoptotic events; platelets treated with CsA plus A23187 become even slightly less apoptotic than platelets treated with the control buffer (Figures 1, 4 and 5). The differences between the inhibitory effect of CsA on $\Delta \Psi \mathrm{m}$ depolarization, platelet shrinkage, microparticle formation

\begin{tabular}{|c|c|c|c|c|}
\hline Apoptotic responses & $n$ & Buffer treatment & A23187 treatment & $P$-value \\
\hline$\Delta \Psi \mathrm{m}$ depolarization (\%) & 5 & $4.0 \pm 0.4$ & $38.5 \pm 7.7$ & 0.0096 \\
\hline PS exposure (\%) & 5 & $3.5 \pm 0.9$ & $98.9 \pm 0.4$ & $<0.0001$ \\
\hline Microparticle formation (N) & 5 & $611 \pm 107$ & $4617 \pm 581$ & 0.0018 \\
\hline
\end{tabular}

Table 1 Quantification of A23187-induced apoptotic responses in human platelets

Apoptotic responses were determined as described in Materials and Methods. Data for platelets treated with control buffer and $10 \mu \mathrm{M}$ A23187 were taken from the experiments presented in Figures $1-5$ and expressed as the percentage cells undergoing $\Delta \Psi \mathrm{m}$ depolarization and PS exposure (\%), mean channel fluorescence (MCF) of FAM-DEVD-FMK probe detecting active caspase-3, number GPIlbilla-positive events acquired in microparticle gate (N) and mean forward scatter (FSC) in platelet gate. Means \pm s.e.m. are presented for indicated number of experiments $(n)$ and $P$-values were calculated by Student's paired $t$-test. 

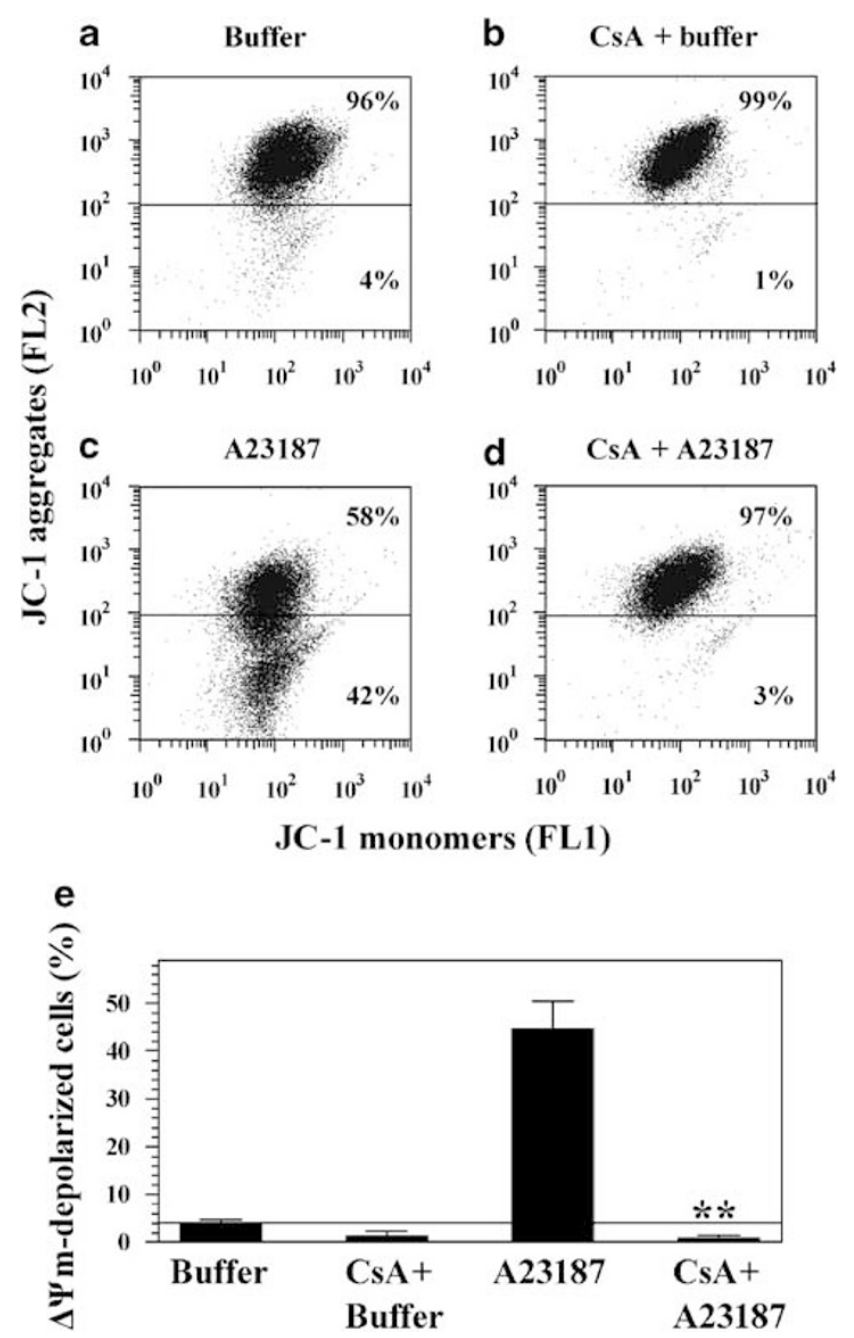

Figure 1 Cyclosporin A inhibits depolarization of mitochondrial inner membrane potential $(\Delta \Psi \mathrm{m})$ in A23187-stimulated human platelets. Depolarization of $\Delta \Psi \mathrm{m}$ was determined by JC-1 fluorochrome. (a-d) Representative dot plots are shown for platelets treated with control buffer (a), $10 \mu \mathrm{M} \mathrm{A} 23187$ (c), and preincubated with $10 \mu \mathrm{M}$ CsA before treatment with buffer (b) or A23187 (d). Depolarization is characterized as the decrease in the content of JC-1 aggregates, as reflected in the decrease of red (FL2) fluorescence. Numbers in the lower parts of dot plots represent the percentage $\Delta \Psi \mathrm{m}$-depolarized cells. (e) Means and s.e.m. for five experiments and $P$-value between A23187- and CsA + A23187-treated platelet groups are shown: ${ }^{*} P=0.01$. $P$-value between $A 23187$ - vs control buffer-treated groups is presented in Table 1. Horizontal line indicates the mean percentage cells undergoing $\Delta \Psi \mathrm{m}$ depolarization in buffer-treated platelet group.

and caspase- 3 activation, characterized by the high mean level of inhibition (86-118\%), were not significant (Figure 6, all $P$-values $>0.05)$, showing that CsA completely prevents triggering these apoptotic responses in A23187-stimulated platelets.

In contrast, differences between the CsA inhibitory effect on PS exposure $v s$ the effect on other apoptotic events were highly significant (Figure $6, P<0.001$ ). This indicates that, in
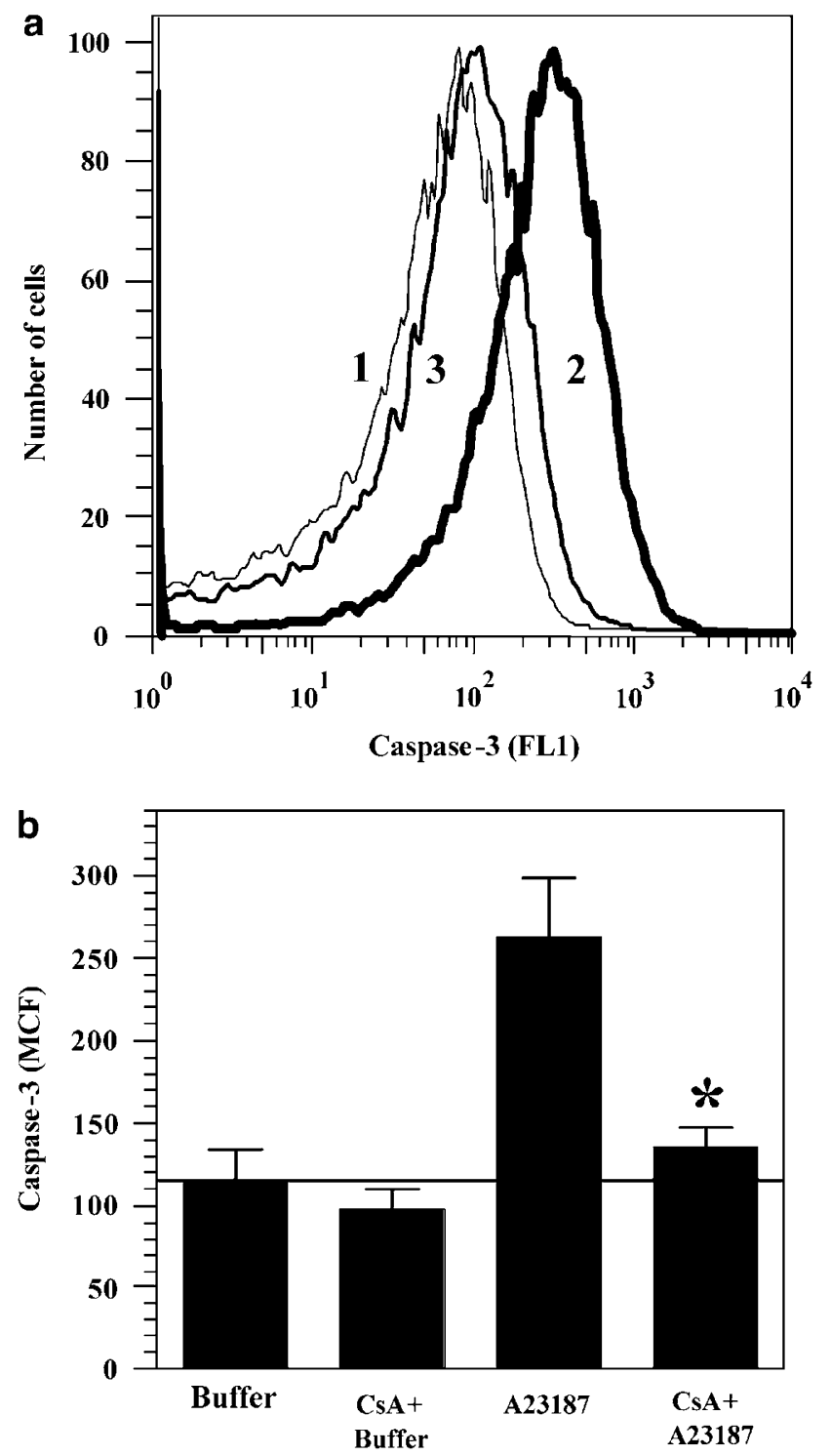

Figure 2 Cyclosporin A inhibits activation of executioner caspase- 3 in A23187-stimulated human platelets. (a) Representative histograms are shown for platelets treated with control buffer (thin line 1), $10 \mu \mathrm{M} \mathrm{A23187}$ (thick line 2) or $10 \mu \mathrm{M} \mathrm{CsA}+10 \mu \mathrm{M} \mathrm{A} 23187$ (mid-thickness line 3). (b) Means and s.e.m. for four experiments and $P$-value between A23187- and $\mathrm{CsA}+\mathrm{A} 23187$-treated platelet groups are shown: ${ }^{*} P=0.02$. $P$-value between A23187- and control buffer-treated groups is presented in Table 1. MCF: mean channel fluorescence of cell-penetrating FAM-DEVD-FMK dye that determines active caspase-3. Horizontal line indicates the mean fluorescence of platelet-bound FAM-DEVD-FMK in buffer-treated platelet group.

comparison with other apoptotic events, A23187-induced PS exposure is much less sensitive to inhibition of MPTP formation by CsA. Moderate inhibitory effect of CsA on PS exposure was persistent in a wide range of CsA concentrations from 1 to $100 \mu \mathrm{M}$ (Figure 7a), and the magnitude of the effect did not depend on the duration of platelet treatment with CsA (Figure 7b) and A23187 (Figure 7c). 

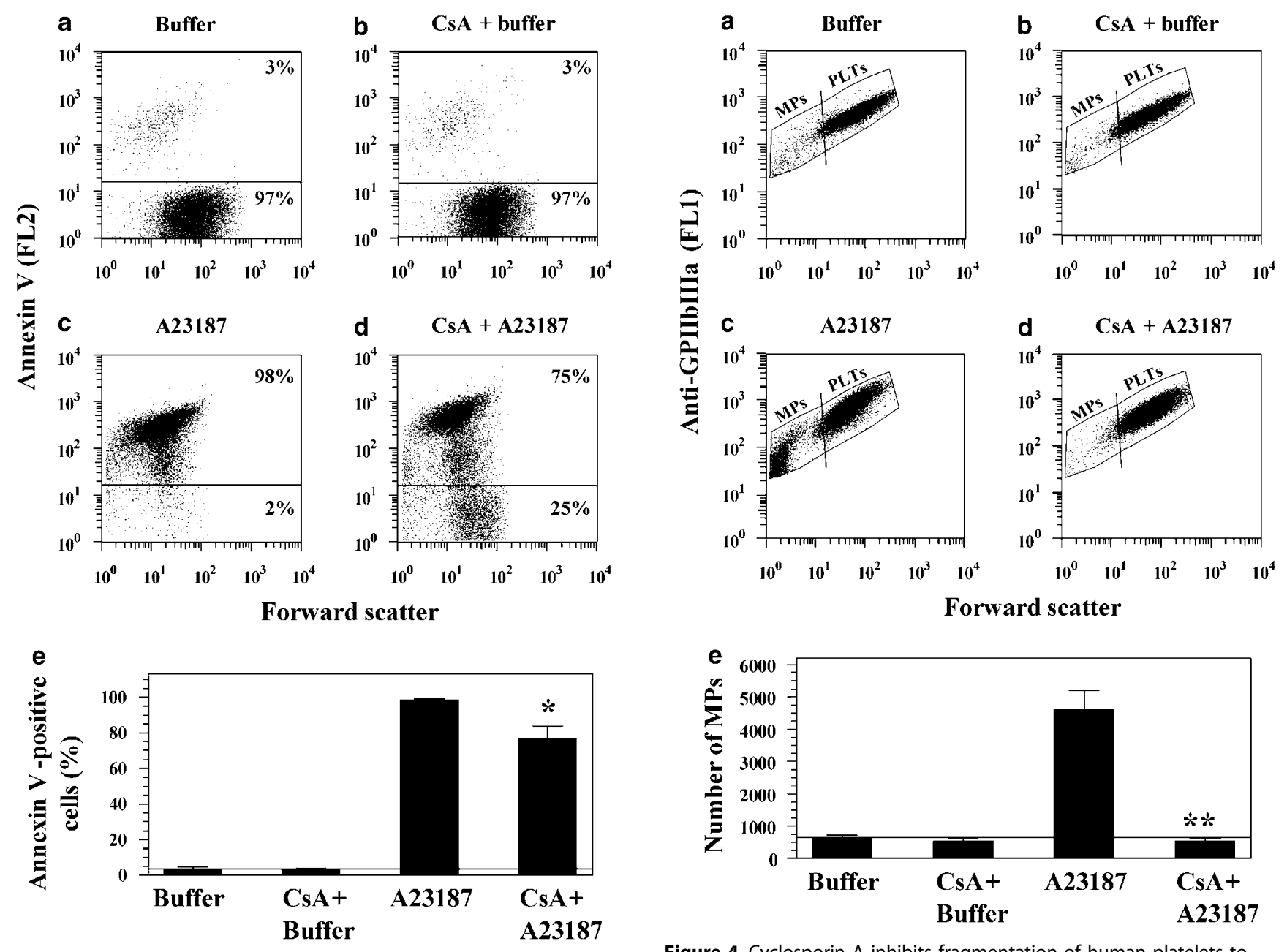

Figure 3 Cyclosporin A inhibits phosphatidylserine exposure in A23187stimulated human platelets. (a-d) Representative dot plots and the percentage annexin V-positive cells (numbers in the upper parts of dot plots) are shown for platelets treated with control buffer (a), $10 \mu \mathrm{M} \mathrm{A} 23187$ (c), and preincubated with $10 \mu \mathrm{M} \mathrm{CsA}$ before treatment with buffer (b) or A23187 (d). (e) Means and s.e.m. for five experiments and $P$-value between A23187- and CsA + A23187-treated platelet groups are shown: ${ }^{\star} P=0.04$. $P$-value between A23187- and buffer-treated groups is presented in Table 1. Horizontal line indicates the mean percentage annexin V-positive cells in buffer-treated platelet group.

\section{Calpeptin, an Inhibitor of Calcium-Dependent Proteinase Calpain, Has No Effect on Mitochondrial Inner Membrane Depolarization}

Wolf $e t$ al $^{19}$ showed that calpeptin, an inhibitor of calciumdependent proteinase calpain, ${ }^{43}$ strongly inhibited some apoptotic events in A23187-treated platelets, including generation of microparticles, and suggested a role for calpain in platelet apoptosis.

In this study, we analyzed the effect of calpeptin on depolarization of mitochondrial inner membrane and extramitochondrial apoptotic events in A23187-stimulated platelets. Figure $8 \mathrm{a}$ shows that, in accordance with the earlier published data, ${ }^{19}$ calpeptin significantly inhibited fragmentation of platelets to microparticles $(P=0.008)$. However,

Figure 4 Cyclosporin A inhibits fragmentation of human platelets to microparticles induced by A23187. Platelets (PLTs) and microparticles (MPs) were stained with anti-GPIlbllla antibody. (a-d) Representative dot plots and gating for PLTs and MPs are shown for platelets treated with control buffer (a), $10 \mu \mathrm{M} \mathrm{A} 23187$ (c), and preincubated with $10 \mu \mathrm{M}$ CsA before treatment with buffer (b) or A23187 (d). The gate of MPs was used for counting microparticles as GPIIbllla-positive events with low forward scatter (FSC), whereas the gate of PLTs was used for analyzing platelet shrinkage from FSC histograms (Figure 5a) and mean FSC values (Figure 5b). (e) Means and s.e.m. for five experiments and $P$-value between A23187- and CsA + A23187-treated platelet groups are shown: ${ }^{* * P}=0.002$. $P$-value between A23187- and buffer-treated groups is presented in Table 1. Horizontal line indicates the mean number of microparticles in buffertreated platelet group.

calpeptin did not affect mitochondrial $\Delta \Psi \mathrm{m}$ depolarization, caspase- 3 activation and PS exposure (Figure 8b), indicating that not all manifestations of platelet apoptosis can be modulated by calpain.

\section{DISCUSSION}

The mitochondrion plays a key role in the control of apoptosis in nucleated cells, and permeabilization of mitochondrial membranes is crucial in apoptotic cell demise. Two general mechanisms are responsible for mitochondrial membrane permeabilization during apoptosis of nucleated 

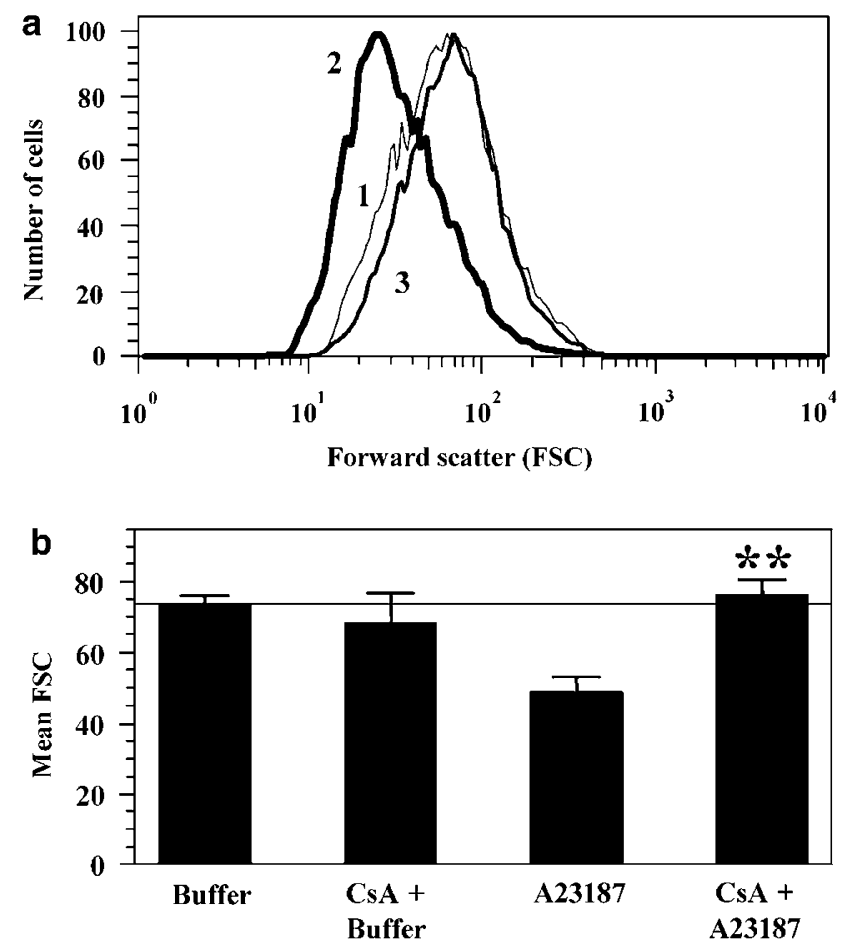

Figure 5 Cyclosporin A inhibits shrinkage of human platelets induced by A23187. (a) Representative histograms are shown for platelets treated with control buffer (thin line 1), $10 \mu \mathrm{M} \mathrm{A} 23187$ (thick line 2) or $10 \mu \mathrm{M}$

$\mathrm{CsA}+10 \mu \mathrm{M}$ A23187 (mid-thickness line 3). FSC histograms were obtained from the platelet gate (PLTs) as shown in Figure $4 a, c$ and d. Note that platelet shrinkage, induced by $\mathrm{A} 23187$, is characterized by FSC downregulation. (b) Means and s.e.m. for five experiments and $P$-value between A23187- and CsA + A23187-treated platelet groups are shown: ${ }^{*} P=0.002$. $P$-value between A23187- and buffer-treated groups is presented in Table 1. Horizontal line indicates the mean FSC of platelets in buffer-treated platelet group.

cells. In the first mechanism, the pore (MPTP) opens in the inner mitochondrial membrane, allowing water and molecules up to $1.5 \mathrm{kDa}$ to pass through. Opening of the MPTP can be triggered by multiple apoptotic stimuli and leads to depolarization of $\Delta \Psi \mathrm{m}$, and swelling of the mitochondrial matrix with following permeabilization of the outer mitochondrial membrane and release of proteins normally confined to the intermembrane space, including cytochrome $c$ and apoptosis-inducing factor. The second mechanism is mediated by members of the Bcl-2 family of apoptosis-regulating proteins acting directly on the outer membrane. ${ }^{1-5,8}$

Numerous reports indicate that MPTP formation plays a critical role in the control of nucleated cell apoptosis. ${ }^{1,2,4,5,8}$ CsA, a pharmacological agent that inhibits MPTP formation in nucleated cells, ${ }^{2,4,5,8,44}$ reduced infarct size in the heart and brain $^{45}$ and enhanced the functional recovery after hypothermic heart preservation. ${ }^{46}$

In contrast to nucleated cells, much less is known about mitochondrial control and the role of MPTP in apoptosis of anucleated platelets. In this study, five key markers were used for characterizing platelet apoptotic events in mitochondria,

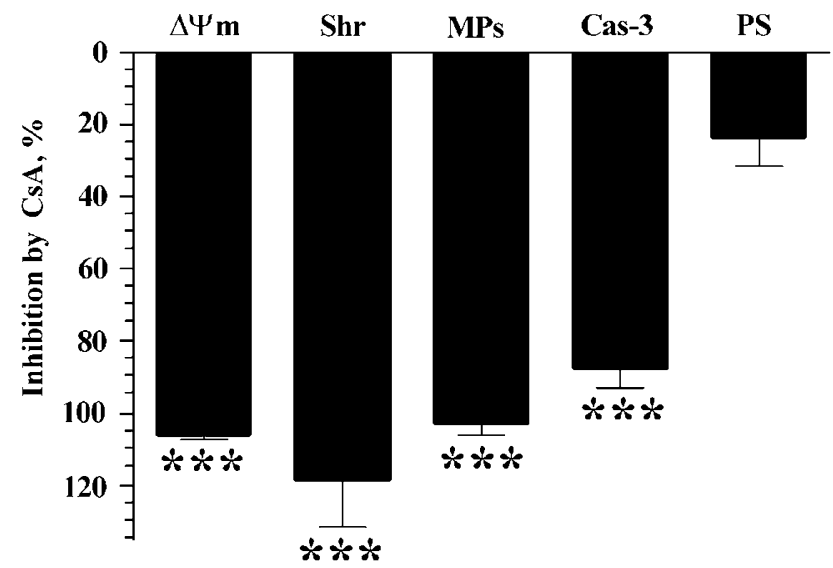

Figure 6 Comparison between inhibitory effects of cyclosporin A on different apoptotic events in A23187-stimulated human platelets. Percentage of inhibition by $C s A$ of $\Delta \Psi \mathrm{m}$ depolarization $(\Delta \Psi \mathrm{m})$, platelet shrinkage (Shr), microparticle formation (MPs), caspase-3 activation (Cas-3) and PS exposure (PS) was calculated from the data presented in Figures 1-5 as described in Materials and Methods. Means and s.e.m. are shown and $P$-values calculated by one-way ANOVA between PS exposure $v s$ other apoptotic events are presented: ${ }^{* *} P<0.001$. Note that preincubation of A23187-stimulated platelets with CsA completely prevents $\Delta \Psi \mathrm{m}$ depolarization, platelet shrinkage, fragmentation of platelets to microparticles, and caspase- 3 activation (differences between these apoptotic events are not significant, $P>0.05$ ) but only moderately inhibits PS externalization.

cytosol, plasma membrane and at the whole-cell level. Apoptotic alterations in mitochondria were detected by the $\Delta \Psi \mathrm{m}$ depolarization, a hallmark of mitochondrial inner membrane permeabilization. Cytosolic apoptotic events were determined by measuring activation of caspase-3, an executioner caspase cleaving vital cell proteins. Apoptotic changes in plasma membrane were analyzed by evaluating PS externalization on the platelet surface and, finally, cellular manifestations of platelet apoptosis were detected by quantifying shedding of membrane-enclosed vesicles (microparticles) resembling apoptotic bodies and by platelet shrinkage. These apoptotic markers were used to characterize apoptosis in platelets treated with a powerful platelet agonist, A23187. We found that all five apoptotic responses were triggered in human platelets, covering different aspects of apoptosis, ranging from an early mitochondrial $\Delta \Psi \mathrm{m}$ depolarization and activation of apoptosis executioner caspase-3 in the cytosol, ultimately culminating in the terminal biochemical and morphological alterations, such as exposure of PS on the cell surface and platelet shrinkage and fragmentation to microparticles (Tables 1 and 2). Earlier, we reported that the same wide spectrum of apoptotic events was induced in platelets exposed to another strong stimulus, a very high pathological shear stresses. ${ }^{24}$ Thus, as an inducer of platelet apoptosis, by the breadth and strength of platelet apoptotic responses, A23187 corresponds to pathological high shear stresses. 
In this study, we also tested the hypothesis that MPTP formation plays a crucial role in the control of apoptosis in A23187-stimulated human platelets. Recently, it has been shown that a targeted deletion of the Ppif gene in null mice (characterized by the complete absence of the Ppif gene product, $\mathrm{CypD}^{9}$ ) results in attenuation of two apoptosisrelated events, $\Delta \Psi \mathrm{m}$ depolarization and PS exposure, in murine-coated platelets costimulated with collagen-mimetic convulxin plus thrombin. ${ }^{40}$ Using another approach, we elucidated whether CsA, an inhibitor of MPTP formation in

a

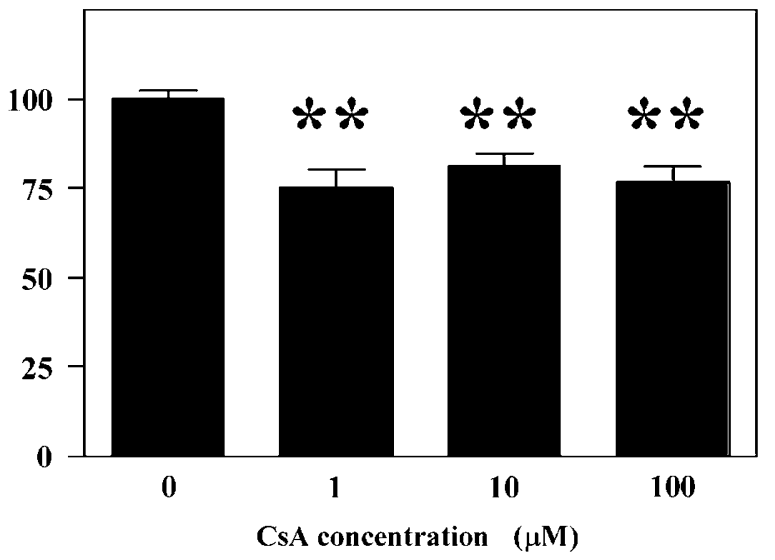

b

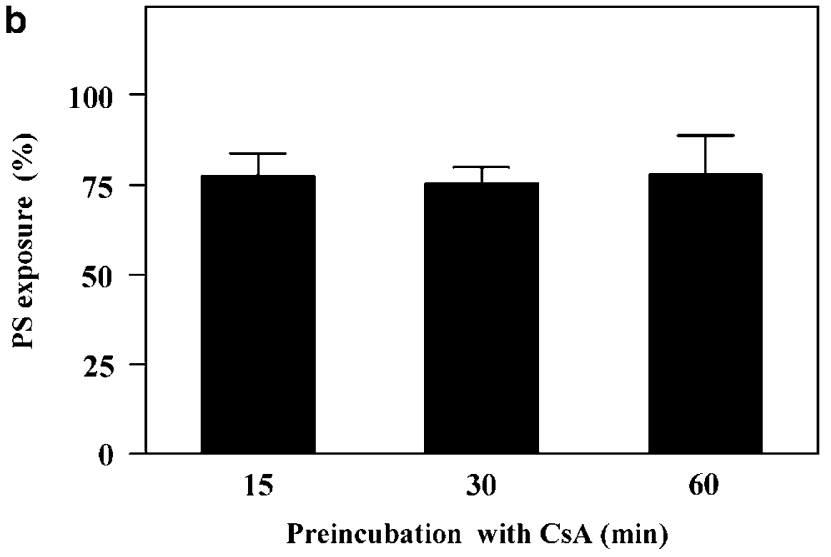

C

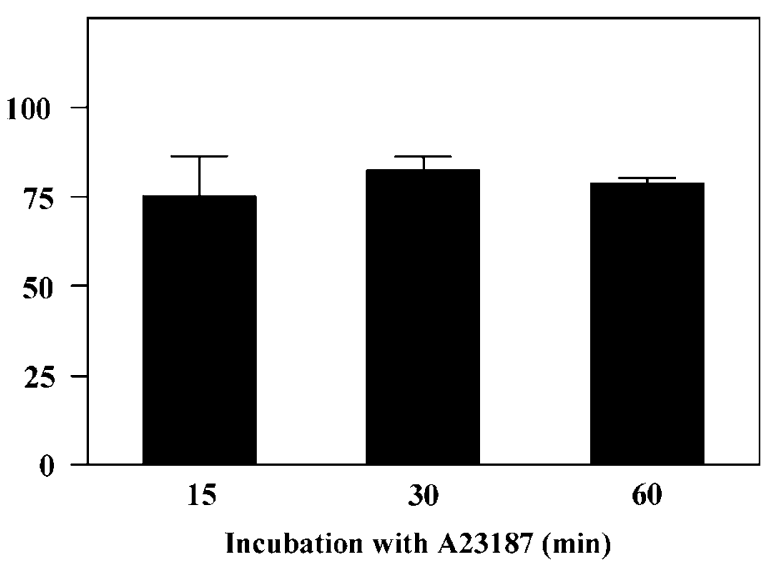

nucleated cells, is able to protect human platelets from apoptosis when platelets, isolated from healthy volunteers with normal functional CypD-producing gene, were stimulated with $\mathrm{Ca}^{2+}$-mobilizing/overloading agent $\mathrm{A} 23187$ (Table 3). The CsA-dependency test allowed us to quantify the contribution of MPTP formation in triggering different apoptotic events in A23187-stimulated platelets and to examine upstream-downstream relationships between MPTP opening and other apoptotic alterations. We showed that CsA completely prevents mitochondrial apoptotic event, $\Delta \Psi \mathrm{m}$ depolarization, and extra-mitochondrial cytosolic event, caspase-3 activation. Surprisingly, CsA is also able to completely prevent two complex terminal manifestations of apoptosis at the whole-cell level, platelet shrinkage and degradation of platelets to microparticles, but only partially $(\approx 25 \%)$ inhibits the third terminal apoptotic event, PS exposure on the platelet surface (Figure 6, Table 2). The moderate effect of CsA on PS exposure is persistent and does not depend on CsA concentration and the duration of platelet treatment with CsA and A23187 (Figure 7).

These results indicate that biochemical apoptotic markers (mitochondrial $\Delta \Psi \mathrm{m}$ depolarization and cytosolic caspase-3 activation) and cellular morphological alterations that accompany terminal phase of apoptosis (platelet shrinkage and fragmentation to microparticles) are strongly dependent on the MPTP formation (Table 2) and are kept under the stringent control of MPTP. However, another terminal apoptotic event (PS externalization) is only moderately dependent on the MPTP formation (Table 2), suggesting that this manifestation of platelet apoptosis is mostly controlled by MPTP-independent mechanisms. Consistent with this, it was recently reported that calcium-ionophore ionomycin increased PS exposure to the same level both in control $\left(\mathrm{CypD}{ }^{+/+}\right)$and $\mathrm{CypD}$-deficient $\left(\mathrm{CypD}^{-/-}\right)$mouse plate-

Figure 7 Effect of cyclosporin A ( $C S A)$ on phosphatidylserine exposure in A23187-stimulated human platelets does not depend on CsA concentration (a) and the duration of platelet treatment with CsA (b) and A23187 (c). Exposure of phosphatidylserine (PS) on the platelet surface was determined by annexin $\mathrm{V}$-binding assay and expressed as the percentage annexin $\mathrm{V}$ positive cells in A23187 only-treated platelets assigned 100\%; all incubations were performed at room temperature. (a) Dependence of PS exposure on CsA concentration. Platelets were preincubated with control diluent buffer $(0 \mu \mathrm{M} \mathrm{CsA})$ or 1,10 and $100 \mu \mathrm{M}$ CsA for 30 min followed by incubation with $10 \mu \mathrm{M} \mathrm{A23187}$ for $15 \mathrm{~min}$. Means and s.e.m. for six experiments and $P$-value between CsA + A23187-treated platelet groups vs A23187 only-treated group are shown: ${ }^{*} P<0.01 ; P$-values between three CsA + A23187-treated platelet groups (1, 10 and $100 \mu \mathrm{M} \mathrm{CsA})$ are not significant: $P>0.05$. (b) Dependence of PS exposure on preincubation time with CsA. Platelets were preincubated with $10 \mu \mathrm{M}$ CsA for 15,30 or $60 \mathrm{~min}$ followed by incubation with $10 \mu \mathrm{M} \mathrm{A23187}$ for 15 min. Means and s.e.m. for three experiments are presented; $P$-values between different

CsA + A23187-treated platelet groups are not significant: $P>0.05$. (c) Dependence of PS exposure on incubation time with A23187. Platelets were preincubated with $10 \mu \mathrm{M} \mathrm{CsA}$ for $30 \mathrm{~min}$ followed by incubation with $10 \mu \mathrm{M} \mathrm{A} 23187$ for 15, 30 or $60 \mathrm{~min}$. Means and s.e.m. for three experiments are presented; $P$-values between different CsA + A23187-treated platelet groups are not significant: $P>0.05$. 


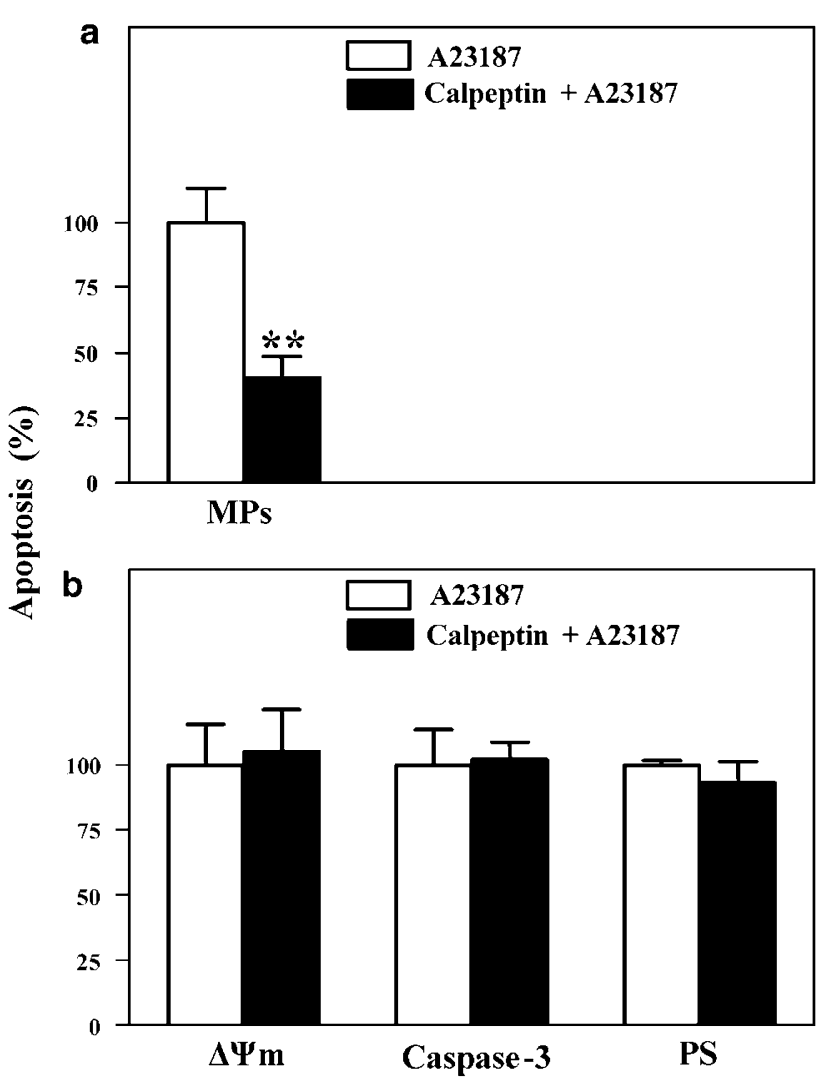

Figure 8 Calpeptin inhibits generation of microparticles (a) but does not affect $\Delta \Psi \mathrm{m}$ depolarization, caspase-3 activation and phosphatidylserine exposure (b) in A23187-stimulated human platelets. Platelets were pretreated with control diluent buffer followed by incubation with $10 \mu \mathrm{M}$ A23187 (open bars) or pretreated with $200 \mu \mathrm{M}$ calpeptin followed by incubation with $10 \mu \mathrm{M}$ A23187 (closed bars). Platelet apoptosis was determined as MP formation (four experiments), $\Delta \Psi \mathrm{m}$ depolarization (four experiments), caspase-3 activation (six experiments) and PS exposure (four experiments), and expressed as the percentage of the averaged values of apoptotic events in platelets treated with A23187 in the absence of calpeptin assigned $100 \%$. Means and s.e.m. are shown and $P$-values calculated between calpeptin + A23187- vs A23187-treated platelet groups: ${ }^{*} P=0.008$ for MPs, $P=0.64$ for $\Delta \Psi \mathrm{m}, P=0.88$ for caspase- 3 and $P=0.40$ for PS. lets. ${ }^{40}$ MPTP-independent PS externalization has been also shown in nucleated cells: CypD ${ }^{+/+}$and $\mathrm{CypD}^{-1-}$ murine thymocytes, and embryonic fibroblasts underwent the same level of PS externalization when exposed to various apoptotic stimuli, including A23187, etoposide, staurosporin and tumour-necrosis factor- $\alpha$ plus cycloheximide. ${ }^{47}$ However, in contrast to calcium-ionophore stimulated platelets, CypD-deficient mouse platelets ${ }^{40}$ and CsA-treated human platelets $^{39}$ stimulated with convulxin plus thrombin are characterized by impaired PS exposure, ie, are strongly dependent on MPTP formation.

Table 3 Two experimental models for analyzing the role of MPTP in platelet apoptosis

\begin{tabular}{|c|c|c|}
\hline Model characteristic & Jobe et $a l^{40}$ & Leytin et $a l^{a}$ \\
\hline Platelet source & Knockout mice & $\begin{array}{l}\text { Healthy human } \\
\text { volunteers }\end{array}$ \\
\hline CypD-producing gene & Deleted & Normal \\
\hline CypD expression & Absent & Present \\
\hline Platelet agonists & Convulxin+thrombin & $\begin{array}{l}\mathrm{Ca}^{2+} \text {-ionophore } \\
\mathrm{A} 23187\end{array}$ \\
\hline $\begin{array}{l}\text { Mechanism of platelet } \\
\text { stimulation }\end{array}$ & $\begin{array}{l}\text { Signaling through the } \\
\text { GPVI+thrombin } \\
\text { receptors }\end{array}$ & $\begin{array}{l}\mathrm{Ca}^{2+} \text { mobilization/ } \\
\text { overloading }\end{array}$ \\
\hline $\begin{array}{l}\text { Reported effects of CsA } \\
\text { on platelet apoptotic } \\
\text { responses }\end{array}$ & $\begin{array}{l}\text { PS exposure in } \\
\text { CypD }^{+/+} \text {murine } \\
\text { platelets }^{\text {b }}\end{array}$ & $\begin{array}{l}\Delta \Psi \mathrm{m} \text { depolarization, } \\
\text { caspase-3 activation, } \\
\text { PS exposure, MP } \\
\text { formation, platelet } \\
\text { shrinkage }\end{array}$ \\
\hline
\end{tabular}

\footnotetext{
${ }^{\mathrm{a}}$ This study.

beported as 'data not shown.'
}

Table 2 Characterization of apoptotic responses in A23187-stimulated human platelets and dependence of these responses on the mitochondrial permeability transition pore (MPTP) formation

\begin{tabular}{|c|c|c|c|c|}
\hline Apoptotic responses & Cellular localization ${ }^{\mathrm{a}}$ & Stage of apoptosis ${ }^{b}$ & Inhibition by $\mathrm{CsA}^{\mathrm{a}}$ & Dependence on MPTP ${ }^{a}$ \\
\hline$\Delta \Psi \mathrm{m}$ depolarization & Mitochondrial & Early & Complete & Strong \\
\hline Platelet shrinkage & Extra-mitochondrial, whole-cell level & Terminal & Complete & Strong \\
\hline Microparticle formation & Extra-mitochondrial, whole-cell level & Terminal & Complete & Strong \\
\hline
\end{tabular}

Table summarizes data (a) presented in this study and (b) obtained in nucleated cells. ${ }^{1,2,4,5,8}$ Dependence of apoptotic responses on MPTP formation was analyzed

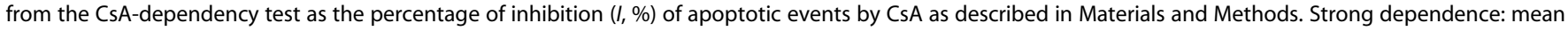
$I>85 \%$. Moderate dependence: mean $I \approx 25 \%$. 
As follows from the quantitative evaluation of the effect of CsA on different apoptotic parameters, $\Delta \Psi \mathrm{m}$ depolarization, caspase-3 activation, platelet shrinkage and release of microparticles are located downstream of MPTP formation. In contrast, it appears that although some processes involved in PS externalization may be located downstream of MPTP formation, they are mainly not associated with and/or are located upstream of MPTP formation.

In this report, we also showed that calcium-dependent proteinase calpain is not involved in depolarization of mitochondrial inner membrane in A23187-stimulated human platelets (Figure 8). We (Table 1) and others have shown activation of caspase-3 in A23187-stimulated platelets ${ }^{18,23,26}$ as well as in platelets stimulated with thrombin, ${ }^{18,26,29}$ collagen, ${ }^{18}$ collagen plus thrombin, ${ }^{18}$ anti-platelet antibodies $^{22,27}$ and long-term platelet storage under blood banking conditions. ${ }^{26}$ Wolf et al ${ }^{19}$ reported caspase-3 activation in vitro in platelet cytosolic extracts treated with cytochrome $c$ and dATP, but did not find caspase-3 activation in whole unfractionated platelets stimulated with A23187, thrombin or collagen plus thrombin. In contrast, these authors presented the evidence that calpain, rather than caspases, promotes several apoptotic events during platelet activation. ${ }^{19}$ The basis for this discrepancy is not known and may reflect the effect of subtle differences in the incubation conditions used in these studies on the assays of caspase activity. It appears that both calcium-dependent proteinases, caspases and calpain, can execute platelet apoptosis.

To investigate whether calpain is involved in depolarization mitochondrial inner membrane and execution of other apoptotic events, we analyzed the effect of calpain inhibitor, calpeptin, on $\Delta \Psi \mathrm{m}$ depolarization, caspase-3 activation, PS exposure and microparticle formation (Figure 8). Experiments with calpeptin were performed in the incubation conditions used for the analysis of the CsA effect on apoptotic parameters, such as preincubation with calpeptin for $30 \mathrm{~min}$ at RT, followed by incubation with $10 \mu \mathrm{M} \mathrm{A} 23187$ for $15 \mathrm{~min}$ at RT. Using this experimental setting, we found that, in comparison with platelets stimulated with A23187 only, pretreatment of platelets with $200 \mu \mathrm{M}$ calpeptin followed by incubation with $10 \mu \mathrm{M} \mathrm{A23187,} \mathrm{significantly} \mathrm{inhibited} \mathrm{gen-}$ eration of platelet microparticles (Figure 8a) but did not affect mitochondrial $\Delta \Psi \mathrm{m}$ depolarization, caspase-3 activation and PS exposure (Figure 8b).

Under different experimental conditions (pretreatment of platelets with $25 \mu \mathrm{M}$ calpeptin for $30 \mathrm{~min}$ at RT and subsequent incubation with $2 \mu \mathrm{M}$ A23187 for $15 \mathrm{~min}$ at $37^{\circ} \mathrm{C}$ ), Wolf et $a l^{19}$ also showed that calpeptin strongly inhibited some apoptosis-related events in A23187-activated platelets, including shedding of microparticles, processing of procaspase- 3 to proteolytically inactive $30 \mathrm{kDa}$ fragment and cleavage of 'apoptotic' substrates, gelsolin and protein kinase $\mathrm{C}-\delta$. However, as in our study (Figure $8 \mathrm{~b}$ ), in these conditions, PS exposure was not affected by calpeptin. ${ }^{19}$ Furthermore, in accordance with our data on the absence of calpeptin effect on caspase-3 activation in unfractionated A23187-treated platelets (Figure 8b), these authors reported that calpeptin was a poor inhibitor of caspase-3 proteinase activity when calpeptin in various concentrations was incubated with purified caspase- 3 in cell-free enzymatic reaction. ${ }^{19}$

Taken together, these results indicate that, under experimental conditions used in this and earlier ${ }^{19}$ studies, calpeptin significantly inhibited microparticle formation ${ }^{19}$ (Figure 8a) and cleavage of apoptotic substrates ${ }^{19}$ but did not affect mitochondrial $\Delta \Psi \mathrm{m}$ depolarization (Figure $8 \mathrm{~b}$ ), caspase-3 activation and PS exposure ${ }^{19}$ (Figure 8b) in A23187-stimulated human platelets. These data suggest that during platelet activation some apoptotic events can be modulated by calpain, whereas the others, including depolarization of mitochondrial membrane, are calpain-independent.

In summary, the data presented indicate that, as in nucleated cells, mitochondria play a crucial role in the control of apoptosis in anucleated platelets and that the formation of MPTP is a key mechanism in mitochondrial control of platelet apoptosis. We showed that MPTP formation in A23187-stimulated human platelets is strongly involved not only in the 'neighboring' MPTP-associated manifestation of mitochondrial apoptosis, $\Delta \Psi$ depolarization, but also in the executioner and terminal apoptotic events, activation of caspase-3, platelet shrinkage and breakdown of platelets to microparticles. However, MPTP formation only moderately contributes to the PS exposure on the platelet surface, suggesting that the externalization of PS only partially depends on the release of proapoptotic factors from permeabilized mitochondria in A23187-stimulated platelets, in contrast to platelets stimulated with physiologically relevant inducers colvulxin plus thrombin.

There is great interest in developing drugs that modulate cell apoptosis. ${ }^{4,54}$ Data presented in this and earlier studies indicate that preservation of mitochondrial integrity with CsA efficiently rescues platelets from a wide spectrum of apoptotic alterations by targeting MPTP, suggesting a novel potential application of this drug for inhibiting platelet demise through apoptosis in thrombocytopenias associated with enhanced platelet apoptosis. ${ }^{22,27}$

\section{ACKNOWLEDGEMENT}

This work was supported by Grant T 6285 from the Heart and Stroke Foundation of Ontario, Canada.

\section{DISCLOSURE/DUALITY OF INTEREST}

The authors declare no competing financial interest.

1. Bernardi $P$, Scorrano $L$, Colonna $R$, et al. Mitochondria and cell death. Mechanistic aspects and methodological issues. Eur J Biochem 1999;264:687-701.

2. Kroemer G, Reed JC. Mitochondrial control of cell death. Nat Med 2000;6:513-519.

3. Danial NN, Korsmeyer SJ. Cell death: critical control points. Cell 2004; 116:205-219.

4. Green DR, Kroemer G. Pharmacological manipulation of cell death: clinical applications in sight? J Clin Invest 2005;115:2610-2617. 
5. Kroemer G, Galluzzi L, Brenner C. Mitochondrial membrane permeabilization in cell death. Physiol Rev 2007;87:99-163.

6. Steller $H$. Mechanisms and genes of cellular suicide. Science 1995;267:1445-1449.

7. Kerr JF, Wyllie AH, Currie AR. Apoptosis: a basic biological phenomenon with wide-ranging implications in tissue kinetics. $\mathrm{Br} J$ Cancer 1972;26:239-257.

8. Crompton $\mathrm{M}$. The mitochondrial permeability transition pore and its role in cell death. Biochem J 1999;341:233-249.

9. Baines $\mathrm{CP}$, Kaiser RA, Purcell $\mathrm{NH}$, et al. Loss of cyclophilin $\mathrm{D}$ reveals a critical role for mitochondrial permeability transition in cell death. Nature 2005:434:658-662.

10. Basso E, Fante L, Fowlkes J, et al. Properties of the permeability transition pore in mitochondria devoid of Cyclophilin D. J Biol Chem 2005;280:18558-18561.

11. Kokoszka JE, Waymire KG, Levy SE, et al. The ADP/ATP translocator is not essential for the mitochondrial permeability transition pore. Nature 2004:427:461-465.

12. Halestrap A. A pore way to die. Nature 2005;434:578-579.

13. Leung AW, Helestrap AP. Recent progress in elucidating the molecular mechanism of the mitochondrial permeability transition pore. Biochim Biophys Acta 2008;1777:946-952.

14. Jacobson MD, Burne JF, Raff MC. Programmed cell death and BCl-2 protection in the absence of a nucleus. EMBO J 1994;13:1899-1910.

15. Schulze-Osthoff K, Walczak H, Droge W, et al. Cell nucleus and DNA fragmentation are not required for apoptosis. J Cell Biol 1994;127:15-20.

16. Martin SJ, Finucane DM, Amarante-Mendes GP, et al. Phosphatidylserine externalization during CD95-induced apoptosis of cells and cytoplasts requires ICE/CED-3 protease activity. J Biol Chem 1996:271:28753-28756.

17. Vanags DM, Orrenius S, Aguilar-Santelises M. Alterations in BCl-2/Bax protein levels in platelets form part of an ionomycin-induced process that resembles apoptosis. Br J Haematol 1997;99:824-831.

18. Shcherbina A, Remold-O'Donnell E. Role of caspase in a subset of human platelet activation responses. Blood 1999;93:4222-4231.

19. Wolf BB, Goldstein JC, Stennicke HR, et al. Calpain functions in a caspase-independent manner to promote apoptosis-like events during platelet activation. Blood 1999;94:1683-1692.

20. Brown SB, Clarke MC, Magowan L, et al. Constitutive death of platelets leading to scavenger receptor-mediated phagocytosis. A caspaseindependent cell clearance program. J Biol Chem 2000;275:5987-5996.

21. Li J, Xia Y, Bertino AM, et al. The mechanism of apoptosis in human platelets during storage. Transfusion 2000:40:1320-1329.

22. Piguet PF, Vesin C. Modulation of platelet caspases and life-span by anti-platelet antibodies in mice. Eur J Haematol 2002;68:253-261.

23. Leytin V, Freedman J. Platelet apoptosis in stored platelet concentrates and other models. Transfus Apheresis Sci 2003;28:285-295.

24. Leytin V, Allen DJ, Mykhaylov S, et al. Pathologic high shear stress induces apoptosis events in human platelets. Biochem Biophys Res Commun 2004;320:303-310.

25. Rand ML, Wang $\mathrm{H}$, Bang KW, et al. Procoagulant surface exposure and apoptosis in rabbit platelets: association with shortened survival and steady-state senescence. J Thromb Haemost 2004;2:651-659.

26. Leytin V, Allen DJ, Mykhaylov S, et al. Thrombin-triggered platelet apoptosis. J Thromb Haemost 2006;4:2656-2663.

27. Leytin V, Mykhaylov S, Starkey AF, et al. Intravenous immunoglobulin inhibits anti-glycoprotein Ilb-induced platelet apoptosis in a murine model of immune thrombocytopenia. Br J Haematol 2006;133:78-82.
28. Leytin V, Allen DJ, Lyubimov $\mathrm{E}$, et al. Higher thrombin concentrations are required to induce platelet apoptosis than to induce platelet activation. Br J Haematol 2007;136:762-764.

29. Lopez JJ, Salido GM, Gomez-Arteta E, et al. Thrombin induces apoptotic events through the generation of reactive oxygen species in human platelets. J Thromb Haemost 2007;5:1283-1291.

30. Mason KD, Carpinelli MR, Fletcher Jl, et al. Programmed anuclear cell death delimits platelet life span. Cell 2007;128:1173-1186.

31. Leytin V, Allen DJ, Mutlu A, et al. Platelet activation and apoptosis are different phenomena: evidence from the sequential dynamics and the magnitude of responses during platelet storage. $\mathrm{Br} \mathrm{J}$ Haematol 2008;142:494-497.

32. Holmsen H. Biochemistry of the platelet: energy metabolism. In: Colman RW (ed). Hemostasis and Thrombosis. Lippincott: Philadelphia, 1987, pp 631-643.

33. Shuster RC, Rubenstein AJ, Wallace DC. Mitochondrial DNA in anucleate human blood cells. Biochem Biophys Res Commun 1988:155:1360-1365.

34. White JG. Platelet structure. In: Michelson AD (ed). Platelets, 2nd edn. Academic Press: San Diego, 2007, pp 45-73.

35. Weyrich AS, Dixon DA, Pabla R, et al. Signal-dependent translation of a regulatory protein, $\mathrm{BCl}-3$, in activated human platelets. Proc Natl Acad Sci USA 1998;95:5556-5561.

36. Lindemann S, Gawaz M. The active platelet: translation and protein synthesis in an anucleate cell. Semin Thromb Hemost 2007;33: 144-150.

37. Zimmerman GA, Weyrich AS. Signal-dependent protein synthesis by activated platelets: new pathways to altered phenotype and function. Arterioscler Thromb Vasc Biol 2008;28:s17-s24.

38. Pereira J, Soto $\mathrm{M}$, Palomo I, et al. Platelet aging in vivo is associated with activation of apoptotic pathways: studies in a model of suppressed thrombopoiesis in dogs. Thromb Haemost 2002;87: 905-909.

39. Remenyi G, Szasz R, Friese $P$, et al. Role of mitochondrial permeability transition pore in coated-platelet formation. Arterioscler Thromb Vasc Biol 2005;25:467-471.

40. Jobe SM, Wilson KM, Leo L, et al. Critical role for the mitochondrial permeability transition pore and cyclophilin $\mathrm{D}$ in platelet activation and thrombosis. Blood 2008;111:1257-1265.

41. Horstman LL, Ahn YS. Platelet microparticles: a wide-angle perspective. Crit Rev Oncol Hematol 1999;30:111-142.

42. Fox JEB, Austin CD, Reynolds CC, et al. Evidence that agonist-induced activation of calpain causes the shedding of procoagulant-containing microvesicles from the membrane of aggregating platelets. J Biol Chem 1991;266:13289-13295.

43. Tsujinaka T, Kajiwara Y, Kambayashi J, et al. Synthesis of a new cell penetrating calpain inhibitor (calpeptin). Biochem Biophys Res Commun 1988;153:1201-1208.

44. Waldmeier PC, Zimmermann K, Lemasters JJ. Cyclophilin D as a drug target. Curr Med Chem 2003;10:1485-1506.

45. Mattson MP, Kroemer G. Mitochondria in cell death: novel targets for neuroprotection and cardioprotection. Trends Mol Med 2003;9:196-205.

46. Rajesh KG, Sasaguri S, Ryoko S, et al. Mitochondrial permeability transition-pore inhibition enhances functional recovery after long-time hypothermic heart preservation. Transplantation 2003;76:1314-1320.

47. Nakagawa T, Shimizu S, Watanabe T, et al. Cyclophilin D-dependent mitochondrial permeability transition regulates some necrotic but not apoptotic cell death. Nature 2005;434:652-658. 